\title{
ENTRE A CARIDADE E O SABER MÉDICO: OS EMBATES EM TORNO DA ASSISTÊNCIA ÀS CRIANÇAS ABANDONADAS NO RECIFE $(1840-1860)^{1}$
}

\section{Between charity and medical knowledge: The clashes surrounding the care of abandoned children in Recife (1840-1860)}

Alcileide Cabral do Nascimento*

\begin{abstract}
RESUMO
Entre os anos de 1840 e 1860, a assistência social no Recife foi duramente criticada, em particular a que era destinada às crianças expostas e à instituição responsável por elas: a Casa dos Expostos. Neste artigo procuro historicizar as tentativas do discurso médico de construir uma noção de salubridade, de organização e gestão das crianças abandonadas e pobres asiladas na Casa dos Expostos que se confronta com os costumes e as práticas caritativas arraigadas profundamente na cultura. A força do discurso médico-higienista ganha concretude com a aprovação do Regulamento dos Estabelecimentos de Caridade de 1847. Mas a tentativa de regular, ordenar, limpar, vigiar e instituir um meio salubre e higiênico se confronta com formas variadas de vida e respostas emanadas das crianças, mulheres, amas de leite e famílias pobres, que não apenas resistiam às tentativas de controle e regulamentação de sua vida, mas também faziam usos diversos da Instituição. $\mathrm{O}$ saber médico precisou de mais tempo e de muitos embates, com diferentes formas de vida e de reinventar no mundo, para galgar hegemonia sobre a população e a cidade, bem como para estabelecer um discurso homogêneo dentro de
\end{abstract}

1 Pesquisa financiada pelo CNPq em 2007-2009.

* Professora de História da Universidade Federal Rural de Pernambuco; Coordenadora do Núcleo de Pesquisas e Estudos em Gênero (NUPEGE); Integrante do GT de História da Infância e da Juventude ANPUH-PE. 
suas próprias fronteiras. Mas sua vitória não se deu sem conflitos, além de ter sofrido algumas derrotas.

Palavras-chave: Assistência à Infância no Recife; Caridade; Saber Médico.

\begin{abstract}
Between the 1840s and 1860s, social assistance in Recife was heavily criticized, particularly because the children exposed and the institution responsible for them: Casa dos Expostos (House of the Exposed). In this article I seek to historicize the attempts of the medical discourse to construct a notion of healthiness, organization and management of abandoned and poor children asylum in the House of the Exposed that is confronted with customs and charitable practices deeply rooted in culture. The strength of the medical-hygienist discourse comes to fruition with the approval of the 1847 Charitable Institutions Regulation. But the attempt to regulate, order, clean, monitor and institute a wholesome and hygienic environment is confronted with varying forms of life and responses emanating from Children, women, daughters and poor families, who not only resisted attempts to control and regulate their lives, but also made various uses of the institution. Medical knowledge needed more time and many battles, with different forms of life and reinventing in the world, to gain hegemony over the population and the city, as well as to establish a homogenous discourse within its own borders. But his victory did not happen without conflicts, besides having suffered some defeats.
\end{abstract}

Keywords: Assistance to Childhood in Recife; Charity; Medical knowledge.

É, porém, digna de lástima a sorte destas crianças, que se recebem na roda para depois a falecer à míngua; e para se fazer ideia basta notar que o ano passado morreram 53 de 76 que entrara, e 108 que existiam. ${ }^{2}$

A situação das crianças abandonadas, ou expostas, em Pernambuco, entre os anos de 1840 e 1860, era mesmo muito grave,

2 Relatório que o Excelentíssimo Presidente da Província, Francisco do Rego Barros, apresentou à Assembleia Legislativa de Pernambuco, na Sessão Ordinária de 1841. Pernambuco: Typographia de Santos e Companhia, 1842. p.13. 
como reconhecia o então presidente da província, Francisco Rego Barros, mais conhecido como Barão da Boa Vista, em 1842, citado acima. Neste período, a Casa dos Expostos estava sob a égide da Administração Geral dos Estabelecimentos de Caridade ${ }^{3}$, instituição criada por decreto de 13 de outubro de 1831, cumprindo a resolução da Assembleia Geral Legislativa e do Governo Regencial, que mandou reunir as casas de caridade do Recife e de Olinda, em Pernambuco, em uma só administração, reorganizando os serviços assistenciais voltados à infância abandonada e órfã. O governo, ao centralizar o atendimento caritativo à criança sem família em uma única instituição, enfrentou um embate entre o saber médico e as práticas caritativas que moldava o perfil dos administradores daquele órgão, bem como resistências difusas à racionalização e à prevenção em curso na gestão da população.

Essa peleja, nem sempre aberta, urdida muitas vezes à surdina, ganha visibilidade na imprensa e se imiscui na rede do poder que fiscalizava os estabelecimentos de caridade, com a crescente influência dos médicos higienistas. Essa medida não é isolada, mas faz parte de um conjunto mais amplo que assinala uma importante transformação da percepção dos problemas sociais que afetava o espaço urbano e envolvia diferentes dimensões da vida na cidade ${ }^{4}$ : a sujeira, as epidemias, o lixo, os cemitérios, o abastecimento e a qualidade da água, a iluminação, a circulação do ar, os transportes. Enfim, descortinavam-se no olhar dos médicos uma urbe insalubre e segmentos da população considerados perigosos - seja para a ordem pública, seja como portadores de doenças incuráveis - ou em perigo, como os recém-nascidos abandonados nas urbes ou crianças potencialmente perigosas, se não fossem educadas e inseridas no mercado de trabalho ao crescerem.

Mas o saber médico era um campo de disputas internas. A verdade sobre o meio social e os elementos constitutivos da sua insalubridade eram motivo de muitas tensões e conflitos entre os

3 COLEÇÃO de Leis do Império do Brasil desde a Independência. Ouro Preto: Tipografia Silva, 1831, v. III, p. 454-456.

4 SANTOS, Manuela Arruda dos. Recife: entre a sujeira e a falta de (com)postura, 1831-1845. 2009. Dissertação (Mestrado em História) - Universidade Federal Rural de Pernambuco. Recife, 2009. 
médicos, e não lugar de consenso hegemônico e homogêneo sobre a cidade e sua população, como demonstram as pesquisas de Manuela Santos e Keyla Guimarães ${ }^{5}$ sobre Pernambuco. Meu trabalho se situa ao lado dos/as autores/as que entendem que a corporação médica e o saber médico não estavam consolidados no século XIX e o diálogo com outras tradições e formas de ver o mundo, a saúde, a doença e o doente eram bastante complexas, como assinala Beatriz Teixeira Weber para o caso do Rio Grande do $\mathrm{Sul}^{6}$.

Apesar dos embates internos, vemos surgir em Pernambuco o Conselho Geral de Salubridade em $1845^{7}$, que funcionou por 10 anos, e, em 1855, a Comissão de Higiene Pública, que durou até 1872, quando foi criada a Inspetoria de Higiene Pública. Até a noção de salubridade ganhar concretude e a medicina ampliar seu raio de ação e influência, foi preciso esperar a década de 20 do século XX, naquilo que Michel Foucault definiu como salubridade para o caso francês:

Salubridade não é a mesma coisa que saúde, e, sim, o estado das coisas, do meio e seus elementos constitutivos, que permitem a melhor saúde possível. Salubridade é a base material e social capaz de assegurar a melhor saúde possível dos indivíduos. E é correlativamente a ela que aparece a noção de higiene pública, técnica de controle e de modificação dos elementos materiais do meio que são suscetíveis de favorecer ou, ao contrário, prejudicar a saúde ${ }^{8}$.

Neste sentido, procuro historicizar as tentativas do discurso médico de construir uma noção de salubridade, de organização e

5 SANTOS, op. cit.; GUIMARÃES, KEILA Danielle Souza. Conselho de Salubridade Pública de Pernambuco: um olhar médico sobre a cidade do Recife entre os anos de 1845-1850. 2010. Dissertação (Mestrado em História) - Universidade Federal Rural de Pernambuco. Recife, 2010.

6 WEBER, Beatriz Teixeira. As Artes de Curar. Medicina, religião, magia e positivismo na República Rio-grandense - 1889-1928. Santa Maria: UFSM; Bauru: Edusc - Universidade do Sagrado Coração, 1999.

7 GUIMARÃES, op. cit.

8 FOUCAULT, Michel. Microfísica do Poder. 5. ed. Rio de Janeiro: Graal, 1985. p.93. 
gestão das crianças abandonadas e pobres asiladas na Casa dos Expostos que se confronta com os costumes e as práticas caritativas arraigadas profundamente na cultura, na administração das instituições asilares, no cotidiano e na forma de viver de grupos étnicos diversificados ao longo dos séculos.

As searas abertas pelos médicos higienistas eram amplas ${ }^{9}$. Mas, a cada flanco aberto, teriam que enfrentar os costumes, profundamente arraigados em práticas religiosas de cunho católicocristãs, sobretudo, de caridade. $\mathrm{O}$ dispositivo da caridade, gestado e colocado em funcionamento através do discurso da Igreja Católica, se consolidou como uma prática de poder, de dominação e de controle. Se, por um lado, estimulava o acolhimento e a criação das crianças enjeitadas por parte dos fiéis, por outro, virava moeda de troca, à medida que abria para o católico mais uma possibilidade de dar visibilidade à sua fé, ampliando seu campo de exercício da misericórdia e da piedade e, com a prática de mais essa boa ação, adiantava seus passos em direção à salvação eterna ${ }^{10}$.

Mas o discurso caritativo não estava incólume às investidas higienistas, ganhava novos tons, flertava com os novos tempos, ao atualizar-se absorvendo alguns novos conceitos. É assim que o administrador dos Estabelecimentos de Caridade, Manoel do Nascimento Costa Monteiro, pleiteava a contratação de um capelão para a Casa dos Expostos, que não teria apenas a missão de encaminhar a alma dos anjinhos, como nos tempos coloniais, ou ainda celebrar missa nos domingos e dias santos, mas precipuamente integrar a "[...] educação da mocidade e instruí-la nos deveres religiosos" $" 11$, inculcar valores, arraigar sentimentos e produzir novas

9 Ver sobre a atuação dos médicos no Recife o trabalho de SIAL, Vanessa Viviane de Castro. Das Igrejas ao Cemitério: políticas públicas sobre a morte no Recife do século XIX. 2005. Dissertação (Mestrado em História) - Universidade Estadual de Campinas. São Paulo/Campinas, 2005 .

10 NASCIMENTO, Alcileide Cabral. A Sorte dos Enjeitados. O combate ao infanticídio e a institucionalização da assistência às crianças abandonadas no Recife (1789-1832). São Paulo: Annablume, 2008. p. 54.

11 Oficio da Administração Geral dos Estabelecimentos de Caridade ao Presidente da Província de Pernambuco. Recife, 13 de janeiro de 1843. Arquivo Público Estadual Jordão Emerenciano (Apeje), Série SC, Cód.1, fl. 226. Ms. 
subjetividades entre os/as enjeitados/as no lastro da tradição católica $^{12}$.

A sorte das crianças abandonadas no Recife, em meados do século XIX, era mesmo "digna de lástima", como afirmava o presidente da província de Pernambuco. O desafio que se colocava era como melhorar o destino dos que sobreviviam ao sistema de criação, sem família, sem padrinho importante, sem eira nem beira. A alta mortalidade, a precária estrutura física do edifício que acolhia os/as enjeitados/as, a falta de recursos, os baixos salários pagos às amas de leite e de criação, o aumento de garotas e garotos crescidos na Casa dos Expostos, sem ter para onde ir, eram alguns dos graves problemas da Instituição.

Como se sabe, a Casa dos Expostos, com sua respectiva roda, foi instituída em 1789, no Recife, com o objetivo precípuo de interditar as práticas infanticidas, tão comuns na cidade, onde bebês eram abandonados nas ruas, becos, monturos e portas de casas e igrejas e devorados por animais como cães e porcos, num "espetáculo de barbárie", como denominou o governador da época. O esforço era combater o abandono "selvagem" de crianças por outra forma, mais civilizada. Não era a vida dos infantes que se queria e se desejava preservar, mas "[...] a promoção de uma nova sensibilidade para com a criação e adoção de práticas de civilidade que se distanciassem do descaso, da insensibilidade para com a morte espetacularizada de recém-nascidos nas ruas"13.

Passados quase 50 anos de criação da Instituição, que recebia bebês de cidades vizinhas, o que se observa é a retomada das práticas de abandono de crianças em portas de particulares e na porta do Hospital da Santa Casa de Misericórdia da cidade de Olinda. Embora não configure uma ação deliberada de eliminação de bebês, eram esses/as miúdos/as " [...] devorados por porcos e cães, ou mortos pelo frio" ${ }^{\prime 4}$, motivando os administradores a solicitar ao então presidente

12 Em 1858 chega um padre europeu para levar adiante essa missão. Cf. Ofício da Administração Geral dos Estabelecimentos de Caridade ao Presidente da Província de Pernambuco. Recife, 28 de outubro de 1858. Apeje, Série Diversos II , Cód.14, fl.83. Ms.

13 NASCIMENTO, op. cit., p. 96-97.

14 Ofício da Administração Geral dos Estabelecimentos de Caridade ao Presidente da Província de Pernambuco. Recife, 13 de janeiro de 1843. Apeje, Série SC, Cód.1, fl.227. Ms 
da província, Francisco do Rego Barros, permissão para instalar uma roda filial na entrada do referido hospital para receber essas crianças de pais anônimos, evitando a morte selvagem desses bebês. Essas crianças deveriam ser remetidas à Casa dos Expostos no Recife; também deveria ser solicitada autorização para contratar uma rodeira com o fito de receber e providenciar os primeiros cuidados aos/às enjeitadinhos/as, com um módico ordenado de $4 \$$ réis mensais (quatro mil réis), pleito que foi atendido imediatamente ${ }^{15}$.

O que se vê em Olinda, como ocorrera no Recife, na esteira de um processo civilizador, é um investimento na sensibilidade em relação à morte e, neste caso, a morte bárbara de crianças. Procurouse construir um estranhamento, uma repulsa, menos à prática de expor, mais à morte selvagem desses pequenos corpos nas ruas e ladeiras da cidade alta, devorados por animais famintos ou sucumbidos pelo frio. E, de pronto, o governador, famoso pelas mudanças que imprimiu à cidade do Recife ${ }^{16}$, sem delongas e considerações, aprovou imediatamente a iniciativa. O saber médico foi arregimentando adeptos. Novas normas alcançaram o aparato assistencial aos pobres e os hospitais públicos, num amplo processo conflituoso de ordenar e higienizar o Recife e sua população.

\section{O saber médico e o Regulamento de 1847}

O que de mais significativo aconteceu neste período, no que tange à assistência social e, em particular, às crianças expostas, foi, sem dúvida, a aprovação do Regulamento de $1847^{17}$. Esse documento,

15 Idem, fl. 227.

16 Sobre o governo do Conde da Boa Vista, ver REZENDE, Antônio Paulo. O Recife: histórias de uma cidade. Recife: Fundação de Cultura da Cidade do Recife, 2002; ANDRADE, Manoel Correia de. Pernambuco Imortal. Recife: Cepe, 1997; CAVALCANTI, Vanildo Bezerra. Recife do Corpo Santo. Recife: Prefeitura Municipal do Recife/Secretaria de Educação e Cultura/ Conselho Municipal de Cultura, 1977.

17 COLEÇÃO de Leis e Decretos da Província de Pernambuco de 1847. Regulamento para os Estabelecimentos de Caridade da Cidade do Recife e sua Administração Geral. Recife, 1847, p. 1-31. 
finalmente posto em execução na administração do governador Antônio Pinto Chichorro da Gama, normatizou o funcionamento burocrático e administrativo das instituições sociais, com regras e interdições a serem seguidas e cumpridas. Por esse regulamento, pode-se dimensionar a força do discurso médico-higienista, numa estratégia de governo voltada à população, ao administrar, inspecionar, classificar, separar, corrigir, avaliar, zelar, anotar, diagnosticar, gerir, fiscalizar, vigiar, reivindicar, propor, por pleitos legais, tudo o que seria necessário ao projeto de centralização dos três estabelecimentos de caridade existentes na capital: o Grande Hospital, o Hospital dos Lázaros e a Casa dos Expostos.

No que tange à administração da Casa dos Expostos, o documento estabelecia "[...] um regente e uma regenta, casada com este; um capelão; uma cozinheira e as serventes indispensáveis" (Art. $23)^{18}$. Chama atenção a amplitude das funções dos regentes. Além de toda a administração da Casa - com a manutenção dos serviços, o controle das amas internas e externas, o cuidado dos bebês lactantes e das crianças maiores, a manutenção da disciplina - teriam ainda que ensinar "[...] aos meninos, de um e outro sexo, a ler, escrever e contar, e, às meninas, a cozer e bordar" (Art. 26) ${ }^{19}$. Essa obrigação demonstra o quanto a educação desses garotos e garotas era de pouca importância, realizada sem critérios de idade, de programa, de avaliação, como já se podia observar na estruturação do ensino que ganhava corpo no Brasil e em Pernambuco depois da Independência $^{20}$. Ademais, essa parca instrução ratifica a exclusão social dos garotos expostos, cuja formação habilitaria apenas para o mercado de trabalho manual. Ao mesmo tempo, reafirmava as hierarquias de gênero, porque só aos meninos era dado acesso a uma aprendizagem que os conectava com o espaço público, restando às meninas o domínio das prendas domésticas, reforçando sua pertinência no âmbito privado.

18 COLEÇÃO, op. cit., p. 5.

19 Ibdem, p. 5.

20 SILVA, Adriana Maria Paulo da. Processos de Construção das Práticas de Escolarização em Pernambuco, em Fins do Século XVIII e a Primeira Metade do Século XIX. Recife: UFPE, 2007; CUNHA, Luiz Antônio. O Ensino de Ofícios Artesanais e Manufatureiros no Brasil Escravocrata. São Paulo: Unesp, Brasília, DF: Flacso, 2000. 
Se a educação não era prioridade nos idos dos anos que seguem, ao menos para esses infantes de pais anônimos o acompanhamento das crianças enfermas o era. Ao facultativo da Casa dos Expostos, caberia "[...] remeter no fim de cada ano um mapa estatístico de sua clínica, e o relatório circunstanciando do Hospital, indicando os meios adotáveis, para que se consiga o seu melhoramento" (Art. 40, $\S 5)^{21}$, além de poder indicar algumas "raparigas (moças enjeitadas) para atuarem como enfermeiras" (Art. $64)^{22}$.

Por essa legislação, observa-se que uma nova racionalidade se entranhava no espaço e nas práticas a inventariar as circunstâncias negativas e positivas da Instituição, dos espaços internos, do asseio e alimentação das crianças, a recomendar a anotação das meizinhas indicadas, a visita aos pequenos enfermos, separar as crianças a partir dos males que portavam, olhar, observar, anotar, diagnosticar, curar, um poder médico que produz saber e, ao mesmo tempo, que intervém higienizando e medicalizando a Casa dos Expostos. Um conjunto de ações burocráticas foi acionado: livros, tabelas e mapas deveriam falar do cotidiano, espedaçá-lo minuciosamente, dar visibilidade aos/as internos/as e a cada um em particular, ao movimento de entrada e saída dos/as enjeitados/as, aos índices de mortalidade e suas causas, bem como revelar a rebeldia dos/as que não se adequavam às decisões sobre sua vida.

A Administração Geral dos Estabelecimentos de Caridade parece ser uma Instituição que, se de um lado, garantiu o ideário cristão-católico, o quinhão de um poder de inspiração cristã frente a uma crescente autonomia de um estado de feições modernizantes, por outro, foi um laboratório do saber médico-higienista, na sua ânsia de controle, disciplina e higienização das instituições e da sociedade. Esse poder que se corporifica com a criação, em 1845, do Conselho de Salubridade de Pernambuco segue a passos curtos as inovações dos países europeus, sobretudo, a França, que, no início do século XIX, havia instituído o Conseil de Salubrité, órgão consultivo cujos membros possuíam a incumbência de analisar os problemas de saúde

21 COLEÇÃO, op. cit., p. 9.

22 Idem, p. 14. 
pública das cidades, propondo as soluções cabíveis aos poderes competentes $^{23}$.

A forte influência francesa se materializava na formação de parte dos médicos brasileiros e pernambucanos. Os aglomerados urbanos eram um grande desafio ao avanço da civilização, em virtude dos problemas sanitários que apresentavam. Era preciso elaborar normas e mecanismos para controlar e limpar o espaço urbano e higienizar a população, prevenindo doenças, ao combater práticas insalubres e antigos costumes coloniais, vistos como primitivos. É sob essa influência e esse ideário que o Barão da Boa Vista insiste, em 1840, junto à Assembleia Legislativa, na criação do Conselho de Salubridade Pública, que acontecerá 5 anos depois e será presidido pelo Dr. Joaquim Aquino Fonseca ${ }^{24}$. Segundo Keila Guimarães, o Dr. Aquino Fonseca, de forma soberba, "[...] fazia publicidade de seu doutorado, fazendo questão de excluir do seu meio todos aqueles que procediam das Faculdades de Medicina da Bahia ou do Rio de Janeiro", sendo alvo inclusive, de muitas piadas jocosas, chegando a receber dos seus oponentes de profissão a alcunha de 'goela de prata" 25 . Enfrentando divergências e oposições no campo do saber médico e sem conseguir o convencimento e a adesão da população, o Conselho foi substituído, em 1853, pela Comissão de Higiene Pública $^{26}$.

É sob a gestão da Comissão que vemos a penetração do saber e da intervenção médica na Casa dos Expostos. A insalubridade, a falta de controle e fiscalização das amas, a alta mortalidade das crianças e a preocupação com a saúde dos infantes são questões prementes desse olhar higiênico na preservação e conservação dos corpos dos infantes. A Administração Geral dos Estabelecimentos será monitorada por este novo olhar, que exigirá relatórios, aumentará a fiscalização e dirigirá novas medidas de salubridade a todas as

23 GUIMARÃES, op. cit., p. 47; FOUCAULT, op. cit.

24 Relatório que o Excelentíssimo Presidente da Província, Francisco do Rego Barros, apresentou à Assembleia Legislativa Provincial de Pernambuco, na Sessão Ordinária do dia $1^{\circ}$ de março de 1840. fl. 8. Disponível em < http://brazil.crl.edu/bsd/bsd/655/000008.html>. Acesso em: 13 jan. 2010.

25 GUIMARÃES, op. cit., p.47.

26 MIRANDA, Carlos A. Cunha. Os Curandeiros e a Ofensiva Médica em Pernambuco na Primeira Metade do Século XIX. Clio. Revista de Pesquisa Histórica, v. 1, n.19, 2001. p. 95-110. 
instituições assistenciais. Nosso enfoque, neste momento, é analisar duas questões que matizaram a interferência e fiscalização da Comissão sobre a administração da Casa: a problemática das amas, internas e externas, nos cuidados dos/as enjeitadinhos/as e o espaço insalubre onde estavam as crianças.

\section{As amas de leite sob o fogo cruzado dos médicos- higienistas}

Um dos sérios problemas que os regentes dos expostos tinham que enfrentar dizia respeito à contratação de amas de leite e de criação para cuidar dos bebês em lactação e em crescimento. Ademais, com os princípios higiênicos e eugenistas em $\operatorname{voga}^{27}$, a antiga prática de utilizar mulheres de cor e pobres era cada vez mais criticada pelo discurso eugenista que ganhava força ${ }^{28}$. Essas mulheres, tão essenciais antanho, passavam a representar um perigo para a degeneração da raça, pelos "males ocultos" que poderiam se infiltrar no corpo da criança por meio do leite e pela imoralidade e permissividade do contato, como expressavam alguns médicos e presidentes de província da época ${ }^{29}$. A prática costumeira de se contratar amas passa a ser intensamente combatida, e a Casa dos Expostos torna-se um espelho pedagógico "aos males" decorrentes desse costume tão comum que alcança as famílias ricas e pobres e que chega até os anos 30 do século XX, apesar das contundentes críticas $^{30}$.

27 Ver, a propósito, SCHWARCZ, Lilia M. O Espetáculo das Raças: cientistas, instituições e questão racial no Brasil (1870-1930). São Paulo: Cia das Letras, 1993.

28 Ver a crítica médica à utilização de amas de leite. Cf. FERREIRA FILHO, Alberto Heráclito. Quem Pariu e Bateu que balance! Mundos femininos, maternidade e pobreza em Salvador, 1890-1940. Salvador: CEB, 2003, p.56-58 e MACHADO, Roberto et al. Danação da Norma. Rio de Janeiro: Graal, 1978, p.355-358.

29 MARTINS, Bárbara Canedo Ruiz. Amas-de-leite e Mercado de Trabalho Feminino: descortinando práticas e sujeitos (Rio de Janeiro, 1830-1890). 2006. Dissertação (Mestrado em História) - Universidade Federal do Rio de Janeiro, Rio de Janeiro, 2006.

30 RAGO, Margareth. Do Cabaré ao Lar. Rio de Janeiro: Paz e Terra, 1987. p.74-84. 
Em abril de 1854, a Comissão de Higiene abre uma "guerra" contra a Administração dos Estabelecimentos de Caridade, apontando as irregularidades administrativas na Casa dos Expostos ${ }^{31}$. Uma grave acusação era figurarem, no livro de entrada, expostos cuja existência era duvidosa. Segundo os diretores, era possível que constassem nomes de crianças inexistentes porque os livros de entrada e saída desses/as enjeitados/as haviam sido perdidos no incêndio que ocorrera na casa do mordomo Joaquim José Mendes em 1824. Somente nos anos de 1840, foram reorganizados os livros com base em antigos cadernos de lançamento feitos pelos regentes "sem a precisa regularidade". Os diretores efetivamente realizaram um exame nos referidos cadernos e identificaram a existência indevida de 42 expostos que deveriam ter sido eliminados por terem falecido, ou saído definitivamente da Casa; diziam ainda ter dúvidas sobre 36 crianças "[...] por se ignorar onde residem as pessoas a quem eles foram entregues", visto que a data de entrega mais recente era de 13 anos! Enfim, concluíram que existiam 274 expostos, sendo 115 do sexo masculino e 159 do feminino ${ }^{32}$.

A Comissão também imputava os diretores a “[...] confiarem os expostos à caridade de pessoas desconhecidas" ${ }^{33}$. Em resposta a essa acusação específica, a Administração da Casa primeiro afirma a legalidade do ato, ao citar os artigos 123 e 126 do Regulamento. Esses artigos tratavam especificamente da contratação de amas internas e externas para a Instituição. Contudo, o artigo 123 dizia textualmente que as amas externas deveriam morar na cidade. Ademais, o artigo 124 estabelecia os critérios de contratação das amas, que deveriam: "1. Estar no gozo de sua perfeita saúde; 2. Ter menos de oito meses de parida; 3. Não ter mais de 40 anos de idade"34. Já o artigo 125 tratava das exigências em relação às amas no momento da contratação: "1. Atestado de boa conduta, passado por uma das autoridades policiais do seu Distrito, ou pelo Pároco

31 Ofício Administração Geral dos Estabelecimentos de Caridade ao Presidente da Província, José Bento da Cunha Figueiredo. Recife, 27 de abril de 1854. Apeje, Série: SC- 02, fls. 25-27.

32 Ofício Administração Geral dos Estabelecimentos de Caridade ao Presidente da Província, José Bento da Cunha Figueiredo. Recife, 10 de maio de 1854. Apeje, Série: SC- 02, fl. 39.

33 Idem, fl.39.

34 COLEÇÃ̃o, op. cit., p. 22. 
respectivo; 2. Carta de fiança de pessoa conhecida, declarando, que por ela responde $[\ldots]^{\prime 35}$.

Se efetivamente os administradores cumpriam essas exigências e as amas portavam a documentação que lhes daria credibilidade, não é possível saber, porque até agora não foram encontradas as cartas de fiança. Todavia, os administradores diziam que seguiram fielmente o que mandava o Regulamento; e alegavam que foi a impossibilidade de se contratar mulheres que se dispusessem a um trabalho tão mal remunerado, como era o de criação dos/as enjeitados/as na cidade do Recife, o motivo pelo qual se viram obrigados a recorrer às que moravam nos arrabaldes da capital, com o intuito primeiro de não deixar perecerem essas crianças. Esses são argumentos razoáveis em virtude da efetiva dificuldade de se contratar amas de leite diante da baixa remuneração e da disputa com o mercado, onde famílias de posses pagavam mais. Portanto, o argumento de que só a necessidade os obrigou a contratar mulheres que residiam em Igarassu e Goiana - arrabaldes distantes 39 e 63 quilômetros, respectivamente, da cidade - "[...] ainda que em pequeno número", como deixavam claro, mas com a garantia de conduta ilibada e que se sujeitavam às condições impostas pela lei, parece ser legítimo ${ }^{36}$. Também alegavam que não podiam impedir as amas de mudarem de domicílio e levarem consigo os/as enjeitados/as, uma vez que costumavam comparecer às revistas de pagamento. Ademais, não havia no Regulamento nenhum impeditivo à mudança de endereço das mulheres contratadas ${ }^{37}$.

Sem dúvida, parte dessas dificuldades em se contratar amas, de leite ou de criação, se devia aos baixos salários pagos a essas mulheres, em geral pobres, que se submetiam a um árduo trabalho por valores aviltantes. Essa situação tendia a se agravar com o passar dos anos, como revela o pedido que a direção dos Estabelecimentos de

35 Ibdem.

36 Ofício Administração Geral dos Estabelecimentos de Caridade ao Presidente da Província, José Bento da Cunha Figueiredo. Recife, 27 de abril de 1854. Ms. Apeje, Série: SC- 02, fl. $24-25$.

37 Ofício Administração Geral dos Estabelecimentos de Caridade ao Presidente da Província, José Bento da Cunha Figueiredo. Recife, 27 de abril de 1854. Ms. Apeje, Série: SC- 02, fls.56-57. 
Caridade fez ao presidente de província, o então Dr. Benevuto Augusto de Magalhães Taques:

Não havendo quem queria sujeitar-se a ser ama interna da Casa dos Expostos pela diminuta quantia de dez mil réis mensais, pedimos a V. Exa. a necessária autorização as referidas amas pagas na razão de $15 \$ 000$ mensais. $^{38^{3}}$

Os administradores da Instituição se referiam às amas internas, mulheres que deveriam cuidar e amamentar os bebês recémchegados à Casa. $\mathrm{O}$ mesmo acontecia com as amas externas, de leite $\mathrm{e}$ secas, que eram mal remuneradas. O diminuto valor motivou a iniciativa das amas de devolver algumas crianças, inclusive lactantes, à Casa, como se pode constatar neste ofício:

Não havendo quem se queira sujeitar à criação de expostos, pela diminuta paga de $4 \$ 000$ os de amamentação e $1 \$ 600$ dos desamamentados, a ponto de terem sido recolhidos alguns; e não tendo a Casa os necessários cômodos, nem amas suficientes para amamentar o crescido número de expostos, que atualmente existe nela; [...].

Pedia, a direção, que o presidente da província: “[...] digne-se a elevar a mensalidade das amas externas em amamentação a $8 \$ 000$ réis mensais, e os em desamamentação a 3 \$200 réis." ${ }^{39}$

Não era pouco o que os Administradores pediam: dobrar os salários das amas, temendo o desfecho funesto do aumento da quantidade de crianças dentro de uma Instituição que não tinha como atendê-las. $\mathrm{O}$ espectro da morte parecia acenar para a vida errante e

38 Ofício da Administração Geral dos Estabelecimentos de Caridade ao Presidente da Província, Dr. Benevuto Augusto de Magalhães Taques. Recife, 26 de agosto de 1858. Apeje, Série: SC- 02, fl.67.

39 Idem, fl.67. 
indefesa desses/as enjeitadinhos/as, daí os administradores buscarem convencer e estimular mulheres, em geral pobres, à maternidade social. Nessas circunstâncias, valia a defesa da direção em contratar mulheres que moravam distante da Instituição, nos bairros longínquos da cidade ou até mesmo em outra cidade. Tudo leva a crer que não tinham mesmo opção, com a premente falta de recursos e os baixos salários atestados.

Como foi visto, o discurso médico-higienista alcança a Casa dos Expostos, penetra a organização, se imiscui no cotidiano, indicando ações. A questão é saber até que ponto esse enunciado tão amplo e diversificado captura a vida, a contingência, os problemas comezinhos do dia a dia. Daí outras questões emergem: como a Instituição lida com a superlotação? Como administra o abandono de crianças crescidas em sua porta? Quais as estratégias de inserção social de garotos e garotas que sobreviveram ao precário sistema de criação? Como a Instituição age diante dos diferentes usos que a população pobre passa a fazer da Casa dos Expostos? Quais as resistências dos/as enjeitados/as ao processo de reordenamento, controle e normatização de sua vida?

\section{A Casa dos Expostos: um abrigo de crianças?}

A década de 1850 irrompe com uma nova e crescente demanda da população mais pobre para as poucas instituições de caráter social que atendiam minimamente as crianças pobres, órfãs e abandonadas. O que fazer com as crianças órfãs pobres? Para onde enviá-las? Como resolver o problema dos/as meninos/as que perambulavam pelas ruas, sem rumo e sem família? Como dar destino aos que cresciam na Casa dos Expostos e lá não podiam continuar? Neste sentido, a Casa vai ganhando outros usos pelas mulheres e famílias pobres. Não era mais o lócus da exposição de bebês, do abandono civilizado, de se evitar o infanticídio ou de se preservar a honra da família, mas onde se deixavam crianças crescidas por diferentes razões. 
Em países como a França, a Espanha e Portugal, as Casas dos Expostos passaram a ser cada vez mais utilizadas por amplo segmento da população pobre, como as mães solteiras, os casais em petição de miséria, as viúvas e viúvos das epidemias que grassavam nas cidades e as prostitutas. Desafortunados de toda ordem, com diferentes motivos, passaram a deixar seus filhos, não mais em tenra idade nas rodas, e sim garotos e garotas crescidos/as na porta das instituições assistenciais $^{40}$. Às vezes, se deixava a criança provisoriamente; outras, os menores eram entregues aos cuidados desses estabelecimentos sem horizonte para resgate, como relatam os/as historiadores/as. Essas Casas iam paulatinamente se convertendo em abrigos e orfanatos para os filhos das camadas pobres e dos desclassificados sociais.

No Recife não foi diferente. $\mathrm{O}$ crescimento populacional verificado no século $\mathrm{XIX}^{41}$, o aumento do custo de vida ${ }^{42}$, as epidemias, como a febre amarela, que grassou no verão de 1849$1852^{43}$, o cólera em $1856^{44}$. Sem dúvida, “[...] esse constante assédio de epidemias denunciava uma insalubridade no ambiente urbano que se tornou alvo do olhar dos higienistas e das autoridades provinciais ao longo do século XIX", como assinala Rosilene Farias ${ }^{45}$. Os enfermos, a mortalidade, as condições de moradia - com uma parcela significativa da população vivendo em mocambos -, o desemprego, a vadiagem nas ruas ${ }^{46}$ fizeram aumentar a pressão sobre a Casa dos Expostos.

40 LAMFUS, Lola Valverde. Entre el Deshonor y la Myseria. Infancia abandonada en Guipúzcoa y Navarra, siglos XVIII y XIX. Bilbao: Univ. Del Paiz Vasco, 1994; MOREDA, Vicente Péres. La infancia Abandonada en España (siglos XVI-XX). Madrid, Imprenta Taravilla, 2005; Marcílio, Maria Luiza. História Social da Criança Abandonada. São Paulo: Hucitec, 1998.

41 CARVALHO, Marcus J. M. de. Liberdade: rotinas e rupturas do escravismo no Recife (1822-1850). Recife: Universitária, 2002.

42 ZANCHETI, Silvio Mendes. O Estado e a Cidade do Recife (1836 -1889). 1989. Tese (Doutorado em Arquitetura) - Faculdade de Arquitetura e Urbanismo, Universidade de São Paulo. São Paulo. 1989;

43 SIAL, Vanessa Viviane de Castro. Das Igrejas ao Cemitério. Dissert. cit. especialmente cap.3.

44 FARIAS, op. cit., p. 159-182.

45 Idem, p. 161.

46 MAIA, Clarissa Nunes. Sambas, Batuques, Vozerias e Farsas Públicas: o controle social sobre os escravos em Pernambuco no séc. XIX (1850-1888). 1995. Dissertação (Mestrado em História) - Centro de Filosofia e Ciências Humanas da Universidade Federal de Pernambuco. Recife: CFCH-UFPE, 1995. 
Os documentos falam do desespero, da última alternativa, apelo à misericórdia de Deus e dos homens, por parte de algumas pobres mães e viúvas ao entregarem as/os filhas/os à Instituição; da perplexidade dos dirigentes dos estabelecimentos de caridade diante da quantidade de garotos e garotas com mais de 12 anos deixados na porta da Casa; das incertezas que pairavam sobre o destino de tantas vidas abandonadas.

A instabilidade da vida dessas crianças andava pari passu com a delicada situação financeira da Instituição que as acolhia. Em agosto de 1855, o procurador do Visconde de Laures solicitou a casa onde se encontrava o Estabelecimento dos Expostos e o Colégio de Órfãs (este criado em 1847), ambos situados à Rua da Aurora. Informava o ofício que o Visconde estava prestes a chegar da Europa e pretendia estabelecer residência na cidade, solicitando a devolução do seu imóvel com a maior brevidade possível. ${ }^{47} \mathrm{O}$ problema estava colocado: para onde deslocar as crianças?

Para isso, foi solicitado ao Facultativo que examinasse as condições de salubridade da antiga Casa dos Expostos, fundada pelo então governador D. Tomás José de Melo, em 1789. Em sua opinião, o edifício, apesar de ser "um pouco baixo", não satisfazendo, portanto, todas as condições higiênicas recomendáveis (altura, ventilação, circulação de ar), era, todavia, "incontestável[mente]" melhor, já que esta antiga Casa preenchia as condições higiênicas "com muito mais escala" do que o edifício onde se encontravam as crianças $^{48}$. Concordava com essa opinião o Dr. Aquino da Fonseca, presidente da Comissão de Higiene Pública, que havia examinado a referida casa $^{49}$.

Com base no entendimento dos médicos sanitaristas, o Governo autorizou a transferência da Instituição para o antigo endereço e informou à direção dos Estabelecimentos de Caridade que a transferência seria efetuada, notícia da qual se dizia ciente a referida

47 Ofício de José João de Amorim, por procuração do Visconde de Laures, aos membros da Comissão Administrativa dos Estabelecimentos de Caridade. Recife, 5 de agosto de 1855. Apeje, série: SC- 02, fl. 178.

48 Ofício de Francisco José da Silva, cirurgião da Casa dos Expostos, ao tesoureiro da Administração Geral dos Estabelecimentos de Caridade. Recife, 21 de maio de 1855. Apeje, série: SC- 02, fl. 125.

49 Idem. 
direção ${ }^{50}$. Neste sentido, a Comissão seguia seu ímpeto de auxiliar o Governo em tudo o que dissesse respeito à saúde de vasto segmento da população, na perspectiva de um enunciado sobre a vida, o corpo, sobre as instituições asilares e a cidade. Aos poucos, o discurso médico-higienista ganhava concretude ao se colocar a serviço da prevenção, do controle e da normatização como ações estratégicas de um governo que buscava paulatinamente ordenar, higienizar e civilizar a urbe e os segmentos da população perigosos ou em perigo.

Em 1854, os administradores dos Estabelecimentos de Caridade, em um ofício ao presidente da província, José Bento da Cunha Figueiredo, falavam da gravidade da situação:

A Administração dos Estabelecimentos de Caridade, tendo reconhecido, que de contínuo se reproduzia o trigésimo abuso de se exporem à porta da roda meninas até da idade de 12 anos, e indecisa sobre o que deveria resolver a este respeito, visto que os Estatutos não previram um tal caso, teve a honra de dirigir-se a $\mathrm{V}$. Exa., que se dignasse autorizá-la a entregar a pessoas de reconhecida probidade aquelas meninas que estavam gravando o estado das despesas já assaz crescida ${ }^{51}$.

Trinta garotas deixadas na porta da Casa dos Expostos com idade de até 12 anos! Apesar de taxar de "abuso", os administradores não sabiam o que fazer com essas meninas. Todavia, ao solicitarem autorização para enviá-las ao trabalho doméstico, a direção da Casa sabia o quanto essa prática era rechaçada pelas expostas, que, muitas vezes, se recusavam a sair da Instituição para trabalhar em casas de família, como recomendava o Regulamento. Considerava-se, portanto, a alternativa de enviá-las para o trabalho doméstico, um

50 Ofício do Conselheiro José Bento da Cunha Figueiredo, presidente da província, à direção da Administração Geral dos Estabelecimentos de Caridade. Recife, 20 de setembro de 1855. Apeje, série: SC- 02, fl.177.

51 Ofício da Junta da Administração dos Estabelecimentos de Caridade ao Presidente da Província, Dr. José Bento da Cunha Figueiredo. Recife, 2 de agosto de 1854. Apeje, série SC02, fl. 78 . 
“[...] recurso idôneo tanto para o benefício das mencionadas expostas quanto para por talvez um dique à imoralidade, que cada vez mais se desenvolve[ia]"52. A prática demonstrava o quanto esse recurso era uma medida exemplar, pedagógica e impopular na tentativa de conter a elasticidade dos usos que segmentos da população pobre passavam a fazer da Instituição em seu benefício. Havia um jogo de poder em que os pobres pareciam manipular o profundo sentimento de caridade e misericórdia que ainda lastreava parte do ideário dos estabelecimentos assistenciais, como admitiam os administradores, ao afirmarem que a caridade cristã não permitia "[...] que se lhes deixassem em abandono" ${ }^{\text {, }}$, como podemos observar no quadro abaixo:

Quadro I Os pedidos de envio de crianças para a Casa dos Expostos (1855-1860)

\begin{tabular}{|c|l|c|c|l|l|l|}
\hline Data & Nome & Idade & Cor & $\begin{array}{l}\text { Proced } \\
\text { éncia }\end{array}$ & Pedido & Despacho \\
\hline $\begin{array}{c}18.01 .1 \\
855\end{array}$ & - & - & - & Órfã & $\begin{array}{l}\text { Recolher } \\
\text { na CE }\end{array}$ & Indeferido \\
\hline $\begin{array}{c}12.07 .1 \\
855\end{array}$ & $\begin{array}{l}\text { Serafim } \\
\text { Lindolfo do } \\
\text { Nascimento }\end{array}$ & 4 & Preto & $\begin{array}{l}\text { Órfão - } \\
\text { enviado } \\
\text { pelo } \\
\text { tutor }\end{array}$ & $\begin{array}{l}\text { Recolher } \\
\text { na CE até } \\
\text { completar } \\
\text { a } \\
\text { instrução }\end{array}$ & $\begin{array}{l}\text { Suplicante } \\
\text { deverá pagar } \\
\text { os custos }\end{array}$ \\
\hline $\begin{array}{c}\text { 23.05.1 } \\
856\end{array}$ & $\begin{array}{l}\text { Joaquim } \\
\text { Moreira } \\
\text { Dias e Clara } \\
\text { Amélia de } \\
\text { Azevedo }\end{array}$ & & & Órfãos & $\begin{array}{l}\text { Recolher } \\
\text { na CE }\end{array}$ & Deferido \\
\hline 23.10 .1 & Anna & & & $\begin{array}{l}\text { Órfã }- \\
\text { pais } \\
\text { vítimas } \\
\text { da } \\
\text { cólera }\end{array}$ & $\begin{array}{l}\text { Recolher } \\
\text { na CE }\end{array}$ & $\begin{array}{l}\text { Indeferido } \\
\text { Não está } \\
\text { previsto no } \\
\text { Regulament } \\
\text { o }\end{array}$ \\
\hline 01.07 .1 & $\begin{array}{l}\text { Isabel e } \\
\text { Constança }\end{array}$ & & $\begin{array}{l}\text { Órfã de } \\
\text { pai }\end{array}$ & $\begin{array}{l}\text { Recolher } \\
\text { na CE }\end{array}$ & $\begin{array}{l}\text { Indeferido } \\
\text { Remetido ao }\end{array}$ \\
\hline
\end{tabular}

52 Ofício da Junta da Administração dos Estabelecimentos de Caridade ao Presidente da Província, Dr. José Bento da Cunha Figueiredo. Recife, 2 de agosto de 1854. Apeje, série SC02 , fl. 78 .

53 Ofício da Junta da Administração dos Estabelecimentos de Caridade ao Presidente da Província, Dr. José Bento da Cunha Figueiredo. Recife, 2 de agosto de 1854. Apeje, série SC02, fl. 78 . 


\begin{tabular}{|c|l|l|l|l|l|l|}
\hline & & & & $\begin{array}{l}\text { enviada } \\
\text { pela } \\
\text { mãe }\end{array}$ & & $\begin{array}{l}\text { Patrimônio } \\
\text { dos Órfãos }\end{array}$ \\
\hline $\begin{array}{c}25.07 .1 \\
857\end{array}$ & Manoel & & & $\begin{array}{l}\text { Orfão - } \\
\text { enviado } \\
\text { pelo } \\
\text { Juiz de } \\
\text { Órfão }\end{array}$ & $\begin{array}{l}\text { Recolher } \\
\text { na CE }\end{array}$ & $\begin{array}{l}\text { Indeferido } \\
\text { Remetido ao } \\
\text { Patrimônio } \\
\text { dos Órfãos }\end{array}$ \\
\hline $\begin{array}{c}25.07 .1 \\
857\end{array}$ & $\begin{array}{l}\text { Tertuliana e } \\
\text { Marcelino }\end{array}$ & & & $\begin{array}{l}\text { Órfãos } \\
\text { de pai e } \\
\text { mãe } \\
\text { remetid } \\
\text { os pelo } \\
\text { Chefe } \\
\text { de } \\
\text { Polícia }\end{array}$ & $\begin{array}{l}\text { Recolher } \\
\text { na CE }\end{array}$ & $\begin{array}{l}\text { Deferido } \\
\text { Remetida a } \\
\text { menina ao } \\
\text { Col.das } \\
\text { Orfãs }\end{array}$ \\
\hline 15.04 .1 & $\begin{array}{l}\text { Alexandrina } \\
\text { e Rozalina }\end{array}$ & 7 & Brancas & $\begin{array}{l}\text { Orfãs } \\
\text { de pai } \\
\text { Mãe } \\
\text { pobre }\end{array}$ & $\begin{array}{l}\text { Recolher } \\
\text { na CE }\end{array}$ & $\begin{array}{l}\text { Indeferido } \\
\text { Remetido ao } \\
\text { Col. das } \\
\text { Órfãs }\end{array}$ \\
\hline $\begin{array}{l}\text { Pai } \\
\text { pobre } \\
860\end{array}$ & & & $\begin{array}{l}\text { Recolher } \\
\text { na CE }\end{array}$ & $\begin{array}{l}\text { Indeferido } \\
\text { Remetido ao } \\
\text { Col. das } \\
\text { Orfãs }\end{array}$ \\
\hline
\end{tabular}

Fonte: Ofícios da Santa Casa, cód.2 (SC-2), anos 1855-57; Ofícios Diversos II, cód. 14 (DII-14) anos 1858-60. Apeje.

$\mathrm{Na}$ amostragem acima, nota-se como os pedidos de envio de crianças para a Casa dos Expostos apontam para o limite das instituições de assistência à infância abandonada, pobre e órfã. Embora a documentação informe apenas a idade de quatro crianças das treze citadas, sabe-se que não se referia a bebês em tenra idade. Majoritariamente eram crianças órfãs da pobreza, da miséria e vítimas das epidemias que ceifaram a vida dos pais. Há exemplos como o de Alexandrina e Rozalina, brancas, com 7 anos de idade, cuja mãe dizia não ter condições de criá-las pela extrema pobreza em que se encontrava, agravada possivelmente pela morte do seu marido, e pedia a "proteção do Governo"54. O único caso que parece escapar dessa miserabilidade é o do pretinho Serafim Rodolfo do Nascimento, 
de 4 anos, cujo tutor estava disposto a pagar a quantia de seis contos e quarenta réis até a idade em que estivesse pronto para receber instrução, o que seria por volta dos 7 a 8 anos de idade ${ }^{55}$. Se os administradores entendiam como abuso, parece saltarem aos olhos as histórias de infortúnios que marcam indelevelmente a vida dos mais pobres e dos seus rebentos.

\section{Considerações finais}

O poder médico sobre a cidade do Recife se intensifica nessas duas décadas e ganha concretude com a aprovação do Regulamento dos Estabelecimentos de Caridade de 1847. Mas a peleja por regular, ordenar, limpar, vigiar e instituir um meio salubre e higiênico se confronta com formas variadas de vida e respostas emanadas de grupos sociais diversos que não apenas resistiam às tentativas de controle e regulamentação de sua vida, mas “[...] interagiam socialmente com criatividade e participaram ativamente das definições do mundo em que viveram", como aponta Beatriz Teixeira para o Rio Grande do Sul, e como se pode aquilatar nas procissões que foram realizadas em 1856 no Recife, cuja população acreditava que a epidemia do cólera era mesmo castigo divino, apesar das críticas de intelectuais e médicos ${ }^{56}$.

A superlotação da Casa, o aumento do abandono de crianças crescidas, a alta mortalidade infantil, os baixos salários pagos às amas de leite, as dificuldades na identificação do parentesco da criança, a indisponibilidade de recursos para dotar as moças casadoiras, foram problemas cotidianos que a prédica higienista tangenciou, mas não deu solução desejada. Paulatinamente as famílias pobres, mestiços e mestiças livres, negros e negras libertos/as, escravos e escravas que

55 Ofício da Junta da Administração dos Estabelecimentos de Caridade ao Presidente da Província, Dr. José Bento da Cunha Figueiredo. Recife, 12 de julho de 1855. Apeje, série SC- 02, fl. 148 .

56 FARIAS, op. cit., p.176-177. 
viviam por conta própria, as viúvas, os viúvos, as prostitutas, os miseráveis do toda ordem, vão fazendo outros usos da Casa dos Expostos, por vezes, deixando crianças como se fora um abrigo temporário, até que as condições econômicas permitissem retomar a criação.

Ao final dos anos de 1850, as instituições de caridade voltam para a alçada da Santa Casa de Misericórdia, que é recriada. Mas do que higienizar espaços, a Casa dos Expostos precisava educar e profissionalizar esses garotos e garotas, que nem sempre aceitam o destino que lhes é dado. As garotas e garotos enviadas/os para casa de famílias como empregadas ou para o trabalho urbano como mão de obra quase escrava, fogem e reinventam sua vida nas ruas da cidade. O poder médico precisará de mais tempo e de muitos embates, com diferentes formas de vida e de reinventar no mundo, para galgar hegemonia sobre a população e a cidade, bem como para estabelecer um discurso homogêneo dentro de suas próprias fronteiras. Mas sua vitória não se deu sem conflitos, além de ter sofrido algumas derrotas, como foi a entrega da Casa dos Expostos para ser administrada pelas Irmãs de Caridade de São Vicente de Paulo ${ }^{57}$ e os Estabelecimentos de Caridade, 2 anos depois, que voltaram para a responsabilidade da Santa Casa de Misericórdia do Recife ${ }^{58}$.

RECEBIDO EM: 01/03/2017 APROVADO EM: 01/06/2017

57 Um ofício da Administração Geral dos Estabelecimentos de Caridade ao Presidente da Província, Sr. Dr. José Bento da Cunha Figueiredo, informa a chegada das Irmãs de Caridade destinadas ao serviço da Casa dos Expostos e pede providências para o seu desembarque no porto do Recife. Recife, 7 de julho de 1858. Apeje, série: SC- 02, fl.397. Ms.

58 COSTA, Francisco A. Pereira da. Anais Pernambucanos. 2. ed. Recife: Fundarpe,1983., v. 4, p. 96. 